\title{
A mathematical model of UITS demand for investment return models
}

\author{
N. Jolic, Z. Kavran \& M. Bukljas \\ Faculty of Transport and Traffic Sciences, University of Zagreb, Croatia
}

\begin{abstract}
According to the latest statistics, $80 \%$ of European Union citizens live in urban areas, and 40\% live in large urban areas of over 200000 inhabitants. On average a European citizen makes 1000 trips per year and half of these are less than $5 \mathrm{~km}$ long. An urban intelligent transport system (UITS) represents a vital subsystem of traffic system and considers wider commercial and operational frameworks within which the flow of passengers and goods is planned and managed. The demand for UITS services can be valorised as highly qualitative, differentiated and derived. While researching transport phenomenon the implementation of models is inevitable and demand models highly desirable. This paper as a contribution to transport modelling improves decision making and planning in the UITS field. Time-variable and space-variable characters of UITS make it more difficult to analyse. One approach to handle space variables is to divide research areas into zones defining the UITS network, in a form suitable for processing. The demand for UITS services is valorised as highly qualitative, differentiated and derived. The task of UITS planning is to forecast and to manage the evolution of equilibrium points over time and space. Modelling these equilibrium points should assist in development and implementation of management strategies and investment programmes. In establishing the equilibration between UITS demand and UITS supply i.e. planning it is essential to ensure an increase in transport efficiency, as it allows small and irregular flows to use shared facilities, a reduction in the importance of location as transport costs and quality of service become more uniform throughout Europe. Keywords: UITS, UITS demand, mathematical model, investment costs, investment return.
\end{abstract}




\section{Introduction}

The need to provide for safe, reliable, and efficient movement of people and goods is held as a core mission of transportation systems and services. In pursuing this mission, one can identify at least five influential themes that are embedded in the creation and operation of a transportation system. These themes are: a) behaviour, b) design, c) performance, d) technology and e) chance (Goulias [1]).

Establishing the urban intelligent transport system - UITS depends on the success of investment return models generated by UITS demand and UITS supply models. This study takes into account results of the work done within the project "Predisposition analyses and strategy of intermodal transport development" financed by Ministry of Sea, Tourism, Transport and Development of the Republic of Croatia, Zagreb, 2007 defining measures which are essential to achieving sustainable development and successful investment return models.

According to the White paper [2], the objective of shifting the balance of transport involves taking consistent measures at a national or local level in the context of other policies - in the area of the urban intelligent transport system policy to strike a balance between modernisation of public services and more rational use of the car, since compliance with international commitments to curb $\mathrm{CO}_{2}$ emissions will be decided in the cities and on the roads.

The first stakeholder conference held on 31st January 2007 linked to the new Green Paper on urban transport brought together representatives from all the sectors that have an interest in the Green Paper. Representatives from the European Commission outlined their plans for the Green Paper. Urban transport significantly contributes to achieving policy objectives in areas such as climate change, energy efficiency, congestion, alternative fuels, modal split, road safety, industrial competitiveness, environment, health and social inclusion.

The expanding urban fabric, lifestyle changes and the flexibility of the private car combined with not always adequate public transport provision have over the last 40 years caused a huge upsurge in traffic in towns. Decentralization of activities or housing may have been flanked by the development of appropriate public transport infrastructure or services; the lack of an integrated policy approach to town planning and transport is allowing the private car an almost total monopoly. That is why this research is done trying to define an urban intelligent transport system demand focused on making better use of public transport and existing infrastructure. The study of UITS demand - UITSD concentrates on one specific aspect of flow of passengers and goods - their relationship with industrial location decisions - asking two key questions:

- What are the main driving forces behind the changes in the location of economic activities?

- How, and to what extent, are these decisions influenced by UITSD considerations? 
In determining the UITS users' requirements it is necessary to predict the possible future development and requirements that do not exist today, but could appear with the development and advancement of technology. Therefore, an increase of flow of passengers and goods intensity, a greater number of users and an increased number of the means introduced by the users into the UITS system may well be expected. The means introduced by the users into the system are considered from the organisational view, and not from the ownership point of view, resulting in the existence of groups of means and elimination of the participants belonging to the same horizontal level. The engagement of a single group depends on the functioning of the rest of the sub-system and restrictions in space and time that depend on the continuity of flow.

The Green Paper on Urban Transport was announced in the mid-term review of the Transport White Paper. It is among the 21 strategic priorities of the Commission for 2007. It will consult all interested parties and be based on their contributions. The Green Paper and its follow-up activities will form the basis for a European Policy on Urban Transport as part of the European transport policy.

\section{Characteristics of urban intelligent transport system demands}

The fact that UITSD model is not based on statistical inference means that it has the important capability of examining the implications of structural changes in underlying markets.

The task of UITS demand planning is to forecast and to manage the evolution of equilibrium points over time and space. Modelling these equilibrium points should assist in development and implementation of management strategies and investment return programmes. In this paper experience of the CIVITAS initiative project [3], and the PRoGRESS project [4] finished at the end of May 2004 and also experience of the public authority experts concerning UITS planning in Croatia was used.

The demand for UITS services is focused on availability of urban transport that is defined in terms of specific criteria such as:

- frequency, security and reliability;

- a commercial and flexible approach to the price negotiation and service quality.

Urban transport planning and simulation modelling continue to be important issues in the $21^{\text {st }}$ century. Urban transport modelling requires mathematical techniques in order to make predictions, which can then be utilised in planning and design. This is the basis for improved decision making and planning in the transport area (Jolic and Kavran [5]).

According to Friesz [6] the specific parameters needed to articulate the constituent sub-models of any transport system (especially an intelligent one), i.e. UITSD, are obtained by statistical and time-series methods; yet, the behaviours of individual demand agents on the UITSD are not based on trends or historical conduct. Rather, these behaviours are modelled mathematically using the results from mathematical programming and game theory. The resulting 
mathematical models are the basis for numerical calculations with modern highspeed digital computers, which determine the end result of various forms of cooperation and competition among those agents. UITS demand takes place over time. This seems a trivial statement but it is the distribution of activities over space which makes for transport demand. In the vast majority of cases, the explicit treatment of space is unavoidable and highly desirable. UITS demand has very strong dynamic elements.

Time-variable and space-variable characters of UITSD make it more difficult to analyse (Ortuzar and Willumsen [7]).

One approach to handle the space variable is to divide research areas into zones defining the urban transport network in a form suitable for processing (simulation modelling). Research areas can be simplified assuming that the zones of interest form a corridor which can be collapsed in urban transport (UITS) analysis. The spatiality of UITS demand can lead to problems of lack of coordination which may strongly influence the UITSD and urban intelligent transport system supply - UITSS equilibrium.

The mathematical definition of the UITSD can be presented as:

$$
\mathrm{UITSD}=\left(\mathrm{T}_{1}, \mathrm{~T}_{2}, \mathrm{O}, \mathrm{C}, \mathrm{E}, \mathrm{R}\right)_{\mathrm{s}, \mathrm{t}}
$$

where:

$\mathrm{T}_{1,-}$ - Technical aspect,

$\mathrm{T}_{2,}$ - Technological aspect,

$\mathrm{O}$ - Organizational aspect,

C - Commercial aspect,

E - Ecological aspect,

$\mathrm{R}$ - Regulatory aspect,

$\mathrm{s,t}$ - Space and time parameters.

Implementing the principle of satisfying UITSD aspects, an alternative option in a functional sense is defined:

$$
\begin{gathered}
\text { P }(\text { UITSD }) \\
\operatorname{utdi}(F)=\text { P i }(\text { UITSD })=\text { FA }(\text { UITSD }), i=1, \ldots, N
\end{gathered}
$$

where:

$P$ - Satisfying principle, utdi (F) - Alternative option in functional sense, urban transport demand, FA (TD) - Functional aspect of transport demand.

\section{Characteristics of urban intelligent transport system supply}

Urban transport as a part of the transport logistics service must be consumed when and where it is produced; otherwise its benefit is lost. Therefore, it is very important to define UITSS and to estimate UITSD with as much accuracy as possible in order to save the resources by planning the supply of urban transport services to it. 
One of the major challenges for urban planning at the end of the century is the problem that the continuous growth in traffic has had on the achievement of sustainable urban development. The particular problems in Europe relate to the shortage of space, higher densities and the protection of open space. It is argued that high-quality liveable cities must be the basis for sustainable urban development and policies should be implemented to achieve that objective, so the outward migration of residents is reversed. Sustainable living requires people to want to live in close proximity in an attractive, affordable urban environment. Recent research in Europe on the options available at the strategic and the city level will be cited to illustrate the actions that are now being considered to achieve sustainable transport in 2020. To achieve this objective, action is required on both the technology of transport and decoupling of transport from economic growth (Banister [8]).

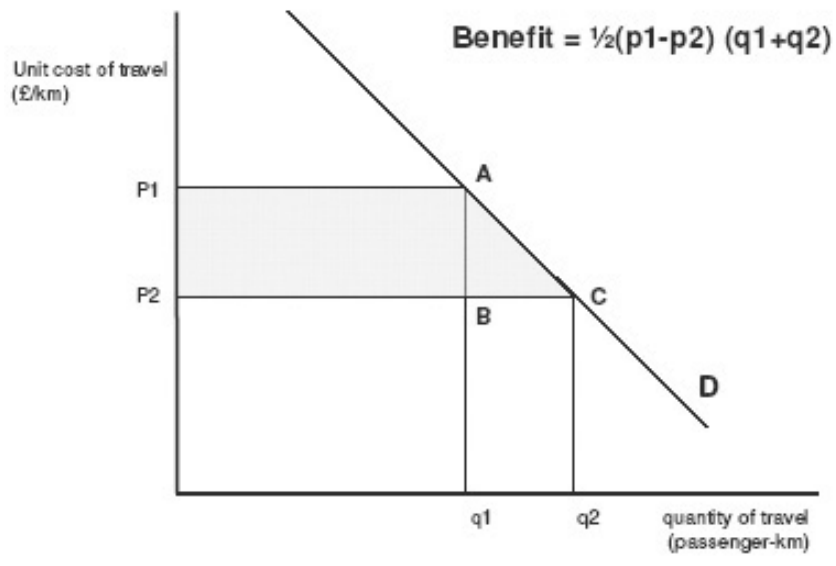

Figure 1: $\quad$ UITS user's surplus.

\section{A mathematical model as a result of equilibrium of UITS supply and UITS demand}

The UITS system changes as levels of services change over space and time. A mathematical model of UITS demand is estimated by the user's surplus, which measures the difference between what the users are willing to pay (derived from the demand function) and what he or she actually pays. Figure 1 illustrates the principle of calculating the user's benefits accomplished by UITS realization. The benefits are calculated by estimating the difference in surplus between situation 1 and situation 2. Given a demand function D, a base situation, without the urban transport policy, gives the quantity q1 (e.g. passenger-km travelled) at the price p1 (e.g. cost of travel per $\mathrm{km}$ ). After the introduction of the urban transport policy, the price drops to $\mathrm{p} 2$ generating additional quantities $\mathrm{q} 2$. The shaded area can be divided into two areas: the rectangle p1ABp2 that represents 
the savings incurred by travellers after the introduction of the urban transport demand policy (e.g. p1 - p2); the triangle A, B, C represents the benefits obtained by the new (induced) travel.

The total benefits can be estimated, assuming a straight line between A and C, as follows: where:

Benefit of urban transport policy (2) over base $(1)=1 / 2(p 1-p 2)(q 1+q 2)$

p1 and p2 - price in base and alternative respectively,

$\mathrm{q} 1$ and q2 - quantity in base and alternative respectively.

In order to determinate the UITS demand model, the measurement of benefits incorporate the travelling cost in addition to the cost of the goods or service purchased by travelling (Figure 2).

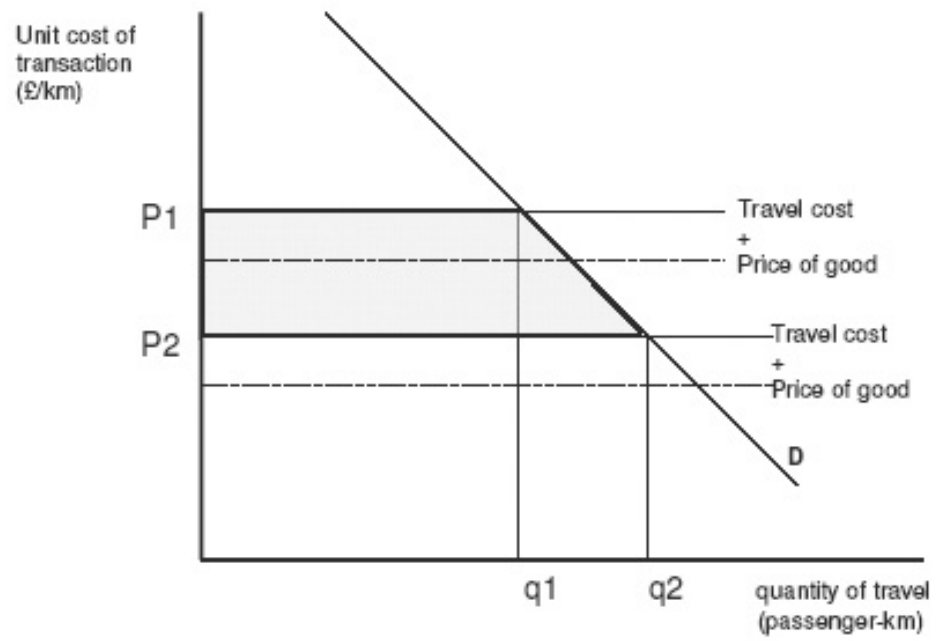

Figure 2: $\quad$ UITS users' surplus that includes travel and the price of the goods.

Finally, according to the defined UITS user's benefits and given a demand function $\mathrm{D}$, the speed of the UITS network $\mathrm{S}$ can be presented as:

$$
\mathrm{S}=\mathrm{f}\{\mathrm{Q}, \mathrm{V}, \mathrm{M}\}
$$

where:

$\mathrm{V}$ - Set of volumes on a network,

Q - Operating capacity,

M - Management system.

The speed can be taken as an initial proxy for a more general indicator of the level of service (LOS) provided by the transport logistics. The capacity $Q$ depends on the UITS management and on levels of investment I, thus: 


$$
\mathrm{Q}=\mathrm{f}\{\mathrm{I}, \mathrm{M}\}
$$

The UITS management can be used to redistribute capacity among the infrastructure, producing Q' and/or giving priority to certain types of users over others, either on efficiency or environmental issues. The level of demand D is dependent on the level of service provided by the UITS and on the allocation of activities A over space:

$$
\mathrm{D}=\mathrm{f}\{\mathrm{S}, \mathrm{A}\}
$$

UITS system will probably change as levels of services change over space and time, so the task of UITS planning is to forecast and to manage the evolution of these equilibrium points over time.

A mathematical model of UITS demand for investment return models represents findings of the (2)-(6) formulas. All defined formulas are to be taken into account. Forming the UITS demand for Croatia UITS was a complex process, UITS requires substantial transport expenditure, both investment and recurring costs. For infrastructure, at the very least, better quality is needed. In many countries and cities in Europe, new infrastructure is still needed and this too will be more costly than in the past.

In establishing the equilibration between UITSD and UITSS it is important to find out the answers on the following issues, as it was defined at the first stakeholder conference regarding preparation of the Green Paper on Urban Transport (European Commission [9]):

1. In which fields can an added value of actions on urban transport be seen?

2. Are there barriers that exist at the EU level that hinder you in implementing an effective and efficient urban transport policy?

\section{Profitability evaluation of UITS investments}

Previous researches make basic contextual analysis of the transport investment, especially with respect to the public sector with intend of yielding a net social benefit to the economy and to society (Townroe and Dabinett [10]).

The methodology for appraising competing investments has been developed in the context of inter-urban rather than intra-urban schemes. Public transport investments within cities have financial, economic and environmental dimensions through the life of the project.

A major concern of all decision makers has been to ensure that there are clear benefits from transport investment proposals. The travel time savings are clear, but the wider economic developments have presented enormous difficulty in terms of both theoretical arguments and empirical evidence (Banister and Berechman [11]).

The objective of the study was to consider UITS demand that generates evaluation methods for UITS investments and make recommendations for investment return models. The results can be used when UITS investments are compared with each other. The conclusion is that traditional cost-benefit analysis (BCA), which was developed for investments in physical infrastructure, does not 
capture all the benefits or costs related to UITS. Economic evaluation methods for UITS investments need improving. This work illustrates that urban intelligent transport system demand and urban intelligent transport system supply could be used as a contribution for forming UITS investment return models.

Recent research in Europe on the profitability evaluation of intelligent transport system investments realized by authors Leviäkangas and Lähesmaa [12] is cited to illustrate the actions that are being considered to achieve effective investment return models.

None of the methods (CBA, AHP...) themselves can reflect all aspects in decision making regarding UITS investments. By using a suitable set of different parameters for UITS demand forming the mathematical model as presented by (2)-(6) in the Republic of Croatia the UITS demand was defined. It was concluded that a mathematical model of UITS demand and UITS supply obtains a wider and more realistic picture of investments and investment return.

\section{Conclusion}

This paper presents the major elements of the debate from a European perspective and it sketches out the choices available to decision-makers, together with the very considerable barriers to implementation. The actions available are grouped under the three headings of technology, economic and financial, and regulation and planning.

The urban intelligent transport system is a complex and expensive system and modelling represents an important tool in planning and investment return options. This paper addresses the issues which arise in evaluating the desirability of proceeding with such investments in the context of scarce public funds.

A major concern of all decision makers has been to ensure that there are clear benefits from transport investment proposals. The travel time savings are clear, but the wider economic developments have presented enormous difficulty in terms of both theoretical arguments and empirical evidence.

Results presented in this paper are confirmed, as scientific results and as practical findings, by work done within the project "Predisposition analyses and strategy of intermodal transport development" financed by Ministry of Sea, Tourism, Transport and Development of the Republic of Croatia, Zagreb, 2007. One topic of this project considers an urban intelligent transport system and for UITS demand establishment the (2)-(6) formulas were implemented. The results of these formulas implementation were more precisely UITS demand determination - more than $25 \%$ realistic measures than demand measures as a result of interviews, traffic monitoring and descriptive statistical method implementation. The obtained UITS demand measures are essential to achieving sustainable development and successful investment return models.

\section{References}

[1] Goulias, K. G.: Introduction to Science, Technology and Transport Systems, Transportation Science and Technology, Elsevier, 2007. 
[2] White Paper, European Transport Policy for 2010: Time to Decide, COM(200)372 12/09/2001.

[3] CIVITAS Initiative project, European Commission, Brussels, 2005.

[4] PRoGRESS project, European Commission, Brussels, 2004.

[5] Jolic, N., Kavran, Z.: Simulation modelling in the function of the intermodal transport planning, Transportation Science and Technology, Elsevier, 2007.

[6] Friesz, T. L: Strategic Freight Networking Planning Models, Handbook of Transport Modelling, Pergamon, Oxford, 2000.

[7] Ortuzar, J. de D., Willumsen, L. G: Modelling Transport, John Wiley \& Sons, New York, 2002.

[8] Banister, D: Sustainable urban development and transport -a Eurovision for 2020, Transport Reviews, Vol. 20, Issue 1, 2000.

[9] European Commission: Preparation of the Green Paper on urban transport, Launch Conference "Urban transport: problems, solutions and responsibilities, Brussels, 31 January 2007.

[10] Townroe, P., Dabinett, G.: The evaluation of public transport investments within cities, The Annals of Regional Science, Springer Berlin, Vol. 29, No. 2, 1995.

[11] Banister, D., Berechman, J.: Transport Investment and Economic Development, Spon Press, 2001.

[12] Leviäkangas, P., Lähesmaa, J.: Profitability Evaluation of Intelligent Transport System Investments, Journal of Transportation Engineering, American Society of Civil Engineers, Vol. 128, Issue 3, 2002.

[13] Bekiaris, E., Nakanishi, Y. N.: Economic impacts of intelligent transportation systems, Elsevier, 2004.

[14] Wymore, W.: Model -based Systems Engineering, CRC Press, London, 1993.

[15] "Predisposition analyses and strategy of intermodal transport development" financed by Ministry of Sea, Tourism, Transport and Development of the Republic of Croatia, Zagreb, 2007.

[16] Short, J.: Sustainable transport: the investment challenge, European Conference of Ministers of Transport, Cambridge, UK, 2002.

[17] Echenique, M., Ponti, M.: Transport Investment and Economic Assessment, University of Cambridge, 2005. 